3
tर
है
जे

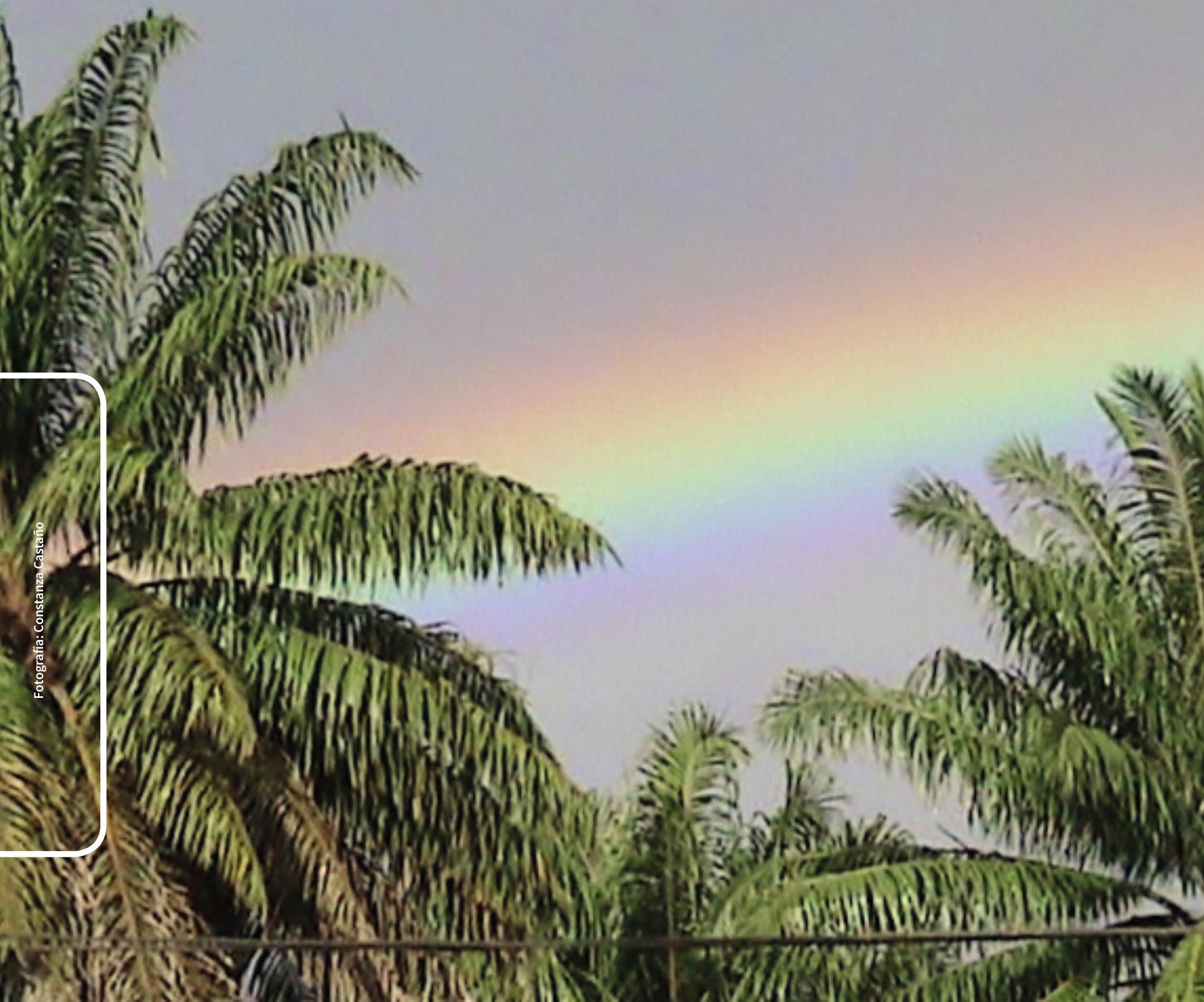




\title{
CUANDO LAS PALABRAS SE HACEN VIDA. REFLEXIONES SOBRE SER MAESTRO DE BIOLOGÍA EN EL PAIÍS DE LA DIVERSIDAD
}

Laura Escárraga Torres ${ }^{1}$

Fecha de recepción: 28 de octubre de 2013

Fecha de aprobación: 13 de diciembre de 2013

...........................................

\begin{abstract}
Yo sueño un país consciente de sus tierras, de sus árboles, de sus mares y de sus criaturas, [...] Yo sueño un país inteligente, es decir, un país donde cada quien sepa que todos necesitamos de todos.
\end{abstract}

(Ospina, 1996)

Ser maestro es posiblemente el viaje más profundo que alguien pudiera vivir, ser maestro va más allá de una profesión y se convierte en un estado en el que vives permanentemente. Y precisamente ese el verbo que debemos aprender a conjugar: vivir. Esta crónica no habla de los grandes "sabios" de la pedagogía, tampoco de las innovaciones en educación y mucho menos de las nuevas modas de la didáctica, la pedagogía y la enseñanza de la biología. Este escrito solo pretende mostrar cómo es que la vida misma es la encargada de llevarnos a despertar las voces que hay dentro de nosotros y que han sido apagadas por el sistema educativo en cual crecimos. Esta historia habla del viaje de la vida... de mi viaje... y sí, habla en primera persona, habla de pasión, de equivocación, de esas cosas que la academia en la que nos insertamos se ha encargado de sacar de nuestros discursos, porque el sentir parece que no es bien visto por el racionalismo pragmático de los ámbitos académicos. ¿Por qué no hablar de emociones, de sentires, de viajes, porque no decir que se aprende con el otro, si eso es la vida?
Yo podría escribir muchas historias de maestros, pero solo conozco bien la mía. Y quizás, para muchos ni siquiera sea una maestra... porque diré que nunca he estado en un salón "profesionalmente", y tampoco he usado la bata con mi nombre en el bolsillo, no he estado en reuniones de padres de familia y tampoco en reuniones de área. No he tenido marcadores de colores y mi letra queda muy torcida en los pizarrones, tampoco espero cada un cheque cada mes.

Diré como muchos de los compañeros con los que crecí, que lo que menos estaba en mis planes era estudiar una licenciatura, ser un profe es algo que nunca contemplé, yo quería ser una bióloga, con bata blanca, con microscopio y con botas de exploradora para descubrir especies nuevas. Pero la vida tenía otros propósitos conmigo, así que la licenciatura llegó a mi vida... mi pensamiento era muy sencillo, "listo, pues yo solo le pongo atención a las clases de biología" y lo otro lo hago por cumplir. Pero como la vida nos lleva a descubrir nuestro camino

1. Licenciada en Biología, Universidad Pedagógica Nacional. escarragalaura@gmail.com 
en situaciones inesperadas, todo ese panorama cambió... de repente las palabras de ciertas maestras fueron viajando por mi ser... se fueron colando por mis pensamientos, haciendo eco en mi corazón. ¿Cómo? aún no lo sé, pero así entendí el poder de la palabra, lo mucho que podemos seducir al otro cuando algo nos apasiona. Aproximarme al significado de ser maestra fue todo un camino, pero así empezó... y luego se convirtió en una pasión, dejó de ser un discurso, y se convirtió en lo que soy y en lo que quiero ser.

En la universidad aprendí a desmoronarme constantemente, aprendí el resentimiento que muchas veces dejamos entrar a nuestras vidas, aprendí que vivimos en un país lleno de magia que se invisibiliza en los salones de clase, aprendí que los mejores maestros fueron mis compañeros con los que compartíamos tardes y mañanas de discursos desesperanzadores... pero a la vez aprendí a luchar por esas pequeñas cosas que encontramos en el camino y que le dan vida a todo lo que somos, aprendí a vivir en la utopía... a dejar que fuera ella quien acompañara mis pensamientos; y claro, también muchas fueron las cosas que desaprendí, muchas cosas que traía conmigo se rompieron con palabras y discursos a veces demasiado duros, pero necesarios para entender que la vida no es lineal, el reevaluar lo que creemos, pensamos y sentimos nos permite ver más claramente el camino que hemos emprendido.

Pensé por mucho tiempo que la academia tenía la razón, que el conocimiento de la universidad era el verdadero, que la ciencia tenía razón, porque tenía a diferencia de las muchas otras formas de explicar el universo, un método concreto y casi infalible. Y eso me envaneció, porque pensé tener la razón y creí tener las certezas y las respuestas para explicar el mundo.

Durante los años de academia entendí que ser profe de biología implica también una responsabilidad social, política, e histórica, no solo somos unas personas al frente de los tableros, ser maestro implica moverse en el mundo, alzar la voz con argumentos cuando ante nuestros ojos se cometen injusticias, cuando vemos que poco a poco nuestra universidad desaparece ante nuestros ojos respaldada por la "ley", fueron muchas batallas libradas durante esos años, algunas se ganaron otras quedaron en el olvido, pero más allá de una lucha por quién gana aprendimos que una unión fuerte genera cambios, cuando tenemos los argumentos y la sinergia de un pensamiento renovador es posible generar cambios, tumbar leyes, y caminar orgullosos por las calles sin el complejo que sienten algunos de ser profes.
Muchos otros momentos y situaciones marcaron mi camino en la universidad, pero me enfocaré particularmente en tres: las salidas de campo, la práctica pedagógica y el trabajo de grado.

Salir implica haber estado adentro (y la academia muchas veces me generó esa sensación de estar dentro, encerrada, de estar alimentándome de pensamientos que se desdibujaban muchas veces en la realidad), las salidas de campo eran como salir de la caverna de Platón, y enfrentarnos a otros mundos y dimensiones de la vivo y de la vida. Reconocer otras especies, otras problemáticas, otros colores, pensamientos y sonrisas me hizo amar un poco más el territorio en el que respiro. En las salidas el fenómeno de lo vivo cobra sentido, deja de ser un pizarrón lleno de letras y se convierte en una sinfonía de orden y caos. Podría asegurar que si preguntan los egresados sobre los momentos en los que la biología cobró sentido, seguramente responderán que fue durante una salida de campo.

Claro, con el tiempo las salidas se fueron reduciendo, hasta puntos donde algunos profes decían que era mejor ir a un museo y ahí reconocer "mejor" la diversidad y lo vivo. Tremenda contradicción, ¿cómo reconocer lo vivo fuera de su contexto? ¿Cómo reconocer lo vivo disecado en frascos y papeles? No digo que algunos museos no son importantes y muestran aspectos interesantes dentro de la ciencia, pero es un poco absurdo reducir a eso la diversidad. Sin embargo, esa es la realidad, parece que fuimos de las últimas promociones que gracias a las salidas de campo, sentimos la sal del mar, el verde y el rio café que baña la selva del Amazonas, que escucharon en las noches estrelladas algunas historias narradas en las voces de sabios indígenas, las montañas que cuentan las historias del pasado en el Eje Cafetero, que subimos al páramo... y parece que esas experiencias se van convirtiendo en leyendas. Son esos espacios los que no podemos dejar que desaparezcan, porque con eso nos quitan gran parte de la formación que debe tener un maestro de biología... conocer al país para quererlo, para comprender que ser "megadiversos, cultural y biológicamente", es mucho más que un discurso. Pero es necesario vivirlo, y sentirlo para entenderlo.

Otro momento que marcó mi vida universitaria fue la práctica educativa, viví demasiadas contradicciones, surgieron ríos de preguntas sin respuestas, y sobre todo me pregunté si de veras ese era mi lugar en el mundo. Yo suponía que los tres años que llevaba en la universidad me habían brindado lo necesario para enfrentarme a esa experiencia, pero no, no había libros que digan que cuando se llegan con ideas un poco diferentes a la escuela 
convencional los profesores alienados por el sistema te ven como un loco, hippie. Tampoco hay manuales que digan que el ambiente de algunos colegios es demasiado tenso, que muchos profes viven en constantes y absurdas guerras con el otro por demostrar quien es "mejor".

Entonces nuevamente surgen frustraciones, demasiadas... sobre todo porque no me cabía en la cabeza que los profesores no pudieran tocar con sus palabras a los niños y que existieran clases tan aburridas. No podía entender, cómo no podía sacarlos al patio al menos a buscar lombrices sin que pegaran el grito en el cielo, era complejo compartir historias sobre las plantas cuando alrededor solo se veían ventanales y asfalto gris.

Tener la práctica en un colegio público es bastante complejo, además el sistema es muy rígido, todo está planeado, hay una ruta de sinsentido muy bien planeada para todo el año. Pero ese fue el reto, con los días se fueron ganando espacios, se fueron sacando sonrisas y me fui equivocando también. Aprendí que la biología no es un fin sino un medio para decir algo, aprendí que es más importante darle un abrazo a un niño que ponerle carita feliz en un examen. La verdad algunos días no tenía ganas de ir a la práctica, a veces me agobiaba con los miles de problemas que tenían los niños, y me sentía peor al no poder hacer nada para ayudarlos. Así que optaba por hacer lo posible porque estuviesen felices las cuatro horas a la semana en que nos veíamos.

Y por allí pasé... recuerdo que en las clases de las tardes nos reunimos con los compañeros a hablar de nuestras prácticas, salían historias chistosas, salían lágrimas de frustración de algunos y surgían más preguntas que siguen alimentándonos.

$Y$ finalmente, el momento culminante: el trabajo de grado, queríamos hacer algo con sentido, queríamos reconocernos dentro de un país diverso, queríamos sentirnos maestros en otros contextos. Así que decidimos viajar al Vichada, es de esos departamentos apartados del país, donde el Estado solo pone sus ojos para explotar sus recursos, de eso lugares que son poco nombrados en los medios de comunicación.

Se produjo una biofilia profunda por el lugar, por el espacio, por los seres y existencias que la poblaban, no sé si les ha pasado pero estar en ciertos lugares despierta en nosotros un éxtasis tan fuerte que se convierte en un total enamoramiento. Entendí el significado de estar viva allí, los anocheceres llenos de estrellas, las mariposas azules que llevan entre sus alas el espíritu de la selva, el río que todo baña, las palabras de los sabedores, el susurro de la brisa... Son espacios momentos y sentires que no encon- traremos en los libros de los sabios ni en los discursos de los académicos. Me sentí tan viva que se me olvidó gran parte de ese conocimiento estructural que se había sembrado en mí, no importaba que no supiera el nombre de las especies, no importaba si no conocía las asociaciones que de establecen entre ellas, lo importante era que estaban allí y que su sola existencia me hacía pensar en lo que significa ser maestro de biología, esa es la verdadera vida, eso es lo vivo. Sinceramente creo que no podemos entender la biología como el estudio de lo vivo sin antes descubrir que estamos vivos.

Para hacer el trabajo de grado con mi compañera Elizabeth Bustos (una de las mejores maestras que he conocido), fue necesario recorrer el río Orinoco hacia arriba, desembocar en un brazo, y luego de navegar en una deslizadora, nos quedamos en una orilla llena de barro. No conocíamos el camino, solo debíamos caminar, así que eso hicimos con más maletas de las necesarias. Estábamos perdidas, pero en un momento muy oportuno apareció un señor de la comunidad que nos indicó el camino para llegar. La sabana estaba quemándonos, pero finalmente llegamos al Internado Caño Hormiga. Los niños nos miraban con risa en los ojos.

No entendíamos nada de lo que nos decían, hablan en Amorua y Sikuani. Los niños nos enseñaron que la sabiduría no requiere de arrugas, que ellos desde sus inocencias y sus pensamientos soñadores tienen la sabiduría en sus manos. Ellos caminaban descalzos en medio del llano, cazaban conejos que luego comían medio asados, ellos nos enseñaron que las plantas y sus saberes no requieren de botánicos. Era su territorio y ellos lo leían nítidamente, con la sabiduría que da el caminarlo.

Con ellos aprendí que en el territorio se siembra el pensamiento y que nosotros somos un territorio, queríamos indagar el lugar de las plantas en la noción de territorio que tienen los niños, y para eso fue necesario caminar con ellos, ir al río, ir a lavar la ropa, ir a las rocas cercanas al internado, fue necesario escucharlos en sus diversos espacios y recorrer con ellos para poder entenderlos.

Luego de todo el proceso de sistematización, terminamos el trabajo de grado. Es una sensación muy extraña la que se siente cuando se termina un ciclo y nunca se planeó lo que seguiría. Se siente incertidumbre y un poco de miedo ante el presente, ante las condiciones que ofrecen los colegios y otras instituciones.

Antes de graduarme empecé a mandar hojas de vida a cuanto trabajo salió por Internet, con los días se convierte como en un pasatiempo (sé que a la mayoría les ha pasado), pero cuando terminé la tesis decidí ir unos

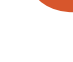


días a descansar. Y estaba muy feliz en esas cuando recibí una llamada, necesitaban una pedagoga para ir al Caquetá. Me puse en contacto, me contaron por encima de que trataba el trabajo, y cuando mencionó comunidades indígenas y proyecto educativo, enseguida acepté. Tenía 5 días para arreglar mi maleta.

Y a los 5 días estaba en el Caquetá, rodeada de un verde resplandeciente y de un río con aguas cristalinas que es básicamente el corazón del pueblo. Luego de entrar en el pensamiento inga... demasiado profundo... las personas me veían como si tuviera las respuestas a sus interrogantes pedagógicos y yo no tenía ni idea de lo que debía hacer. Así que opté por escucharlos, por entrar en sus corazones, por vislumbrar sus pensamientos y hacerlos poco a poco parte de los míos.

La comunidad inga tiene una sensibilidad muy grande hacia su territorio, han aprendido a escuchar las voces de los seres y existencias que recorren sus caminos. El trabajo básicamente se desarrollaba en el colegio Yachaikury (caminos de aprendizaje). Y el nombre decía mucho de lo que se pretendía, y era volver a recorrer esos caminos de aprendizaje que los mayores habían pisado.

Y poco a poco se vuelven a recorrer esos caminos, el presente hace que no sean los mismos, y que muchas cosas hayan cambiado. Pero es un mérito aún más grande que a pesar de la influencia de la violencia, la coca, y el bombardeo de los medios que pretenden masificar aún más el pensamiento, se levanten jóvenes hablando en la lengua que les enseñaron sus padres, y pueden sentir las voces de sus territorios, y pueden pelear con argumentos con las petroleras y las ong, sobre por qué no pueden pisar sus tierras.

Del proceso en el Caquetá me quedaron las voces de la selva y del río, encontré en ese lugar un hogar y cuando puedo ir siempre me siento como en casa. Pero el trabajo terminó, así que muy a mi pesar debía volver a enfrentarme a la ciudad gris nuevamente.

En Bogotá conseguí trabajo en un colegio francés, ¡duré un día! o menos de un día, el colegio era en una casa antigua, con salones reducidos. El salario era muy malo, pero el ambiente en general no era tan malo. Esa noche no pude dormir pensando si había tomado una buena decisión, en ese momento necesitaba el trabajo porque no tenía dinero, pero a la vez sentía que si aceptaba estaba encerrándome a mí misma. Así que al siguiente día, les dije que yo no era la maestra que necesitaban. Cuando salí por las puertas del colegio, me sentí libre otra vez y feliz de haber tomado esa decisión, pero claro, debía asumir las consecuencias y eran seguir sin empleo.
Un día estaba en medio de mi hobbie de mandar hojas de vida y de repente recibo un correo, era de una ong a la cual le había enviado mi hoja de vida solicitando ser voluntaria hace muchos meses y que ya había olvidado. El mensaje decía "se necesita voluntario en Bolivia". Se requería de una agrónoma para trabajar con comunidades quechuas.

Cuando uno se adentra en los pensamientos que se han tejido en territorios y corazones indígenas entonces cada palabra va quedando anclada en nuestra sangre, y con el tiempo nos hacemos uno con el territorio con la vida y con los pensamientos. Como dije, el pensamiento indígena cuando penetra en la vida queda arraigado para siempre. Por eso, enseguida dije que sí.

$Y$ en este momento de la vida me encuentro aquí, en Bolivia, que ha sido una experiencia de aprendizaje de la diversidad, una diversidad que no está oculta, ni relegada, sino una diversidad que se siente orgullosa de ser, y de vivirse día a día, el quechua no se esconde con vergüenza, por el contrario cada palabra es tan sonora que pareciera que estuviera en armonía con las montañas y lagunas que bañan este territorio.

Una de las cosas que más me han sorprendido es cómo se ve el indígena-campesino quechua, aquí ellos viven sin fingimiento, orgullosos de tener sus raíces en el tiempo de los incas y orgullosos de vivir en la matriz de los Andes. Las montañas y la mayoría de territorios no están cercados, se respeta lo propio y lo ajeno, cada cual sabe qué lugar le corresponde.

Para mí ha sido toda una experiencia pues supuestamente buscaban una agrónoma y supuestamente lo soy, mi título universitario dice "licenciada en biología", sin embargo, la tierra siempre va conmigo, así que el tiempo que viví en el campo y las enseñanza de campesinos y agricultores a lo largo de la vida deberían ser el incentivo para convertirme en esa agrónoma que necesitaban.

También se requirió un poco de libros, pero sobre todo la tierra es la que enseña. Ahora en momentos en que nuestro país atraviesa una crisis agraria, es donde más se necesitan quizás no tantos agrónomos de esos que les dicen a los campesinos las dosis de veneno exactas que deben poner a sus cultivos (para que produzca más rápido), de esos agrónomos al parecer hay muchos y en parte es debido a ellos la gran crisis, por décadas se han desconocido y borrado lentamente las prácticas agrícolas de miles de campesinos.

Ese afán de desarrollo es una locura frenética que nos lleva simplemente más rápido a la muerte, pero debo decir que aquí las cosas son un poco diferentes. En estos 
meses que llevo como "agrónoma", me di cuenta que se requiere de una filiación profunda por la tierra para poder sembrarla. No debería ser el miedo a que desaparezca lo que nos impulse a cuidarla, simplemente debe ser el amor, y la reciprocidad hacia todo lo que nos ofrece.

Y este es mi camino... aunque no tengo una lista de asistencia, ni la bata blanca, y aunque en vez de reuniones de área me reúna con padres y madres de familia que me hablan en quechua y no les entiendo mucho que digamos... a pesar de todo hay muchos niños y niñas y algunas otras personas que me dicen "profe". Y me siento feliz de ser esa profe, para algunos, un poco hippie quizás, pero es una forma de ser maestra.

En el camino he podido mirar a los ojos a la diversidad y por eso me pregunto cómo pretenden que se formen los maestros de biología en Colombia, cómo alcanzar a reconocer al menos de vista la verdadera diversidad, biológica y cultural. Cómo recrear la vida a través de museos donde parte de la vida está muerta. No entiendo cómo algunos maestros se empeñan en que los estudiantes sigan realizando sus prácticas dentro de la ciudad, cuando hay tanta vida por descifrar, sentir, estudiar y pensar en otros lugares de nuestra geografía.

No digo que no se pueda realizar una buena práctica sobre la enseñanza de la biología en la ciudad, lo que digo es que teniendo un país tan diverso deberíamos promover sumergirnos en sus miles de ríos, en meternos en las montañas que lo adornan y en contemplar las risas y los pensamientos de tantas personas tan diversas que vivimos en él, es llegar a una dimensión donde podamos hacer parte de otras realidades.
La biología y su enseñanza implica ver la vida a la cara, no es solo una profesión, no entiendo como muchos maestros han entrado en un estado de dormancia provocado por el sistema educativo en el que se ven inmersos, y olvidaron lo vivos que nos sentimos cuando fuimos al Amazonas, olvidaron los miles de colores que tienen la diversidad, y al parecer también olvidaron los sueños que teníamos de contagiar a los demás de esa pasión que sentíamos al ver un "bicho" volar, o una planta nueva, o el croar de miles de ranas en unas noches estrelladas, o el sabor de aguas desconocidas, la arena debajo de nuestros pies y el sabor a la vida.

No sentimos eso con dibujos en el tablero, ni con videos, ni con las diapositivas, la vida no puede morir en los trazos de los marcadores... Quizás la palabra clave es la vida... esa que se quebranta ante la desesperanza que algunas veces nos inunda, pero es esa misma que nos lleva sentir que el tejido de nuestros pensamientos nos pueden llevar a construir un mejor país, donde la vida y lo vivo dejen de ser teorías incrustadas en los estantes de las bibliotecas y se convierta en una experiencia que emerge desde nuestro ser y se teje con el universo.

Si me preguntaran que significa ser maestra de biología en el país de la diversidad, yo podría decir que ser maestra es un viaje que nace en nosotros, pero que se construye y se transita con el otro, con los otros... 